\title{
Application of Virtual Scenario Teaching in Spoken English Teaching
}

\author{
https://doi.org/10.3991/ijet.v16i18.25659 \\ Mengqing $\operatorname{Han}^{1}$, Shanshan $\mathrm{Niu}^{2}\left({ }^{\bowtie}\right)$ \\ ${ }^{1}$ Shijiazhuang University of Applied Technology, Shijiazhuang, China \\ ${ }^{2}$ Huaxin College of Hebei GEO University, Shijiazhuang, China \\ poppy 19890809 @sina.com
}

\begin{abstract}
The ultimate goal of learning the English language is oral communication. Virtual scenario teaching (VST) provides the speaking and listening opportunities for learners of spoken English, and allows students to actively participate in the creation of an English environment. Based on VST, this paper summarizes the status quo of spoken English teaching, applies VST to the teaching of spoken English, and evaluates the teaching effect. The results show that VST enhances the students' ability of language expression, and stimulates their learning interest. With the aid of VST, students can master relevant knowledge, learn spoken English more fluently, and acquire better skills of oral expression. About $95 \%$ of teachers speak highly of VST. The research results lay a theoretical basis for reforming and improving the teaching of spoken English.
\end{abstract}

Keywords_-oral communication, virtual scenario teaching (VST), English environment, teaching effect, language expression

\section{Introduction}

Now in China, VST has become an important teaching method and has achieved very good results in English teaching [1]. However, due to the influence of many factors, spoken English teaching hasn't been valued by people, and it is always on the fringe of English class [2,3]. At present, the teaching modes of schools generally spend most of the class hours on the teaching of English grammar, reading, and writing, and less attention has been paid to oral English [4]. With the advent of the era of convergence media, now more teachers have introduced multimedia and new technologies into their classroom teaching, and these have greatly enriched the presentation forms of various teaching methods, including the VST $[5,6]$.

VST is a novel teaching method that outperforms that traditional classroom teaching methods which are dull and monotonous, and the utilization of teaching tools has been greatly increased [7, 8]. In the Internet era, the efficiency of information access is getting higher, which has greatly diversified the English teaching modes [9]. The new media types and network technologies enable VST to display the teaching content using new presentation and application forms [10]. In VST, teachers need to 
create various scenarios or emotional atmosphere for students in specific time and space ranges, and carry out teaching activities based on students' emotional cognition, logical thinking, and actual behavior [11, 12]. VST could adapt to the age characteristics of students, trigger their enthusiasm for language learning, and make full use of the features of the created scenarios to urge students to learn actively, thereby relieving students' degression and boredom for language learning [13].

Language is a tool for meaningful communication in various scenarios, it is meaningless if the scenarios have been ignored [14, 15]. Oral English is the basic form of language expression, and it has the characteristics of flexible and loose, and sometime it's accompanied by communicative means and language scenarios [16, 17]. The teaching of spoken English needs to create a language communication atmosphere for students, and help them to use verbal language to convey, communicate, and express in English through relevant teaching activities [18]. Since VST has broad content and scope, teachers can teach spoken English using scenarios that are suitable for the development characteristics of students at different learning stages [19,20]. Based on VST, this paper attempts to figure out the status quo of spoken English teaching in schools, and explore the application effect of VST in oral English teaching and the achieved teaching results.

\section{$2 \quad$ Application of VST in spoken English teaching}

English learning exercises learners' abilities in listening, speaking, reading, and writing in English, and the cultivation of such abilities is inseparable from the language scenarios [21]. The application of VST can vitalize the spoken English teaching in traditional classrooms, mobilize students' enthusiasm and initiative for spoken English learning, and increase their interest in spoken English class [22]. Owing to its merits of suitable lecturing mode, abundant media resources, and the constantly improving teaching facilities, VST has been widely applied in the teaching of spoken English [23]. Figure 1 lists the principles of applying VST in spoken English teaching, including the authenticity principle, participatory principle, communicative principle, instructional principle, and entertaining principle. The actual teaching process of VST needs to pay attention to the training of students' communication skills, create channels and bridges for their communication, and set scenarios flexibly to reduce communication gaps [24].

The scenarios in VST can be roughly divided into three types: intuitive scenarios, real scenarios, and imaginary scenarios [25]. VST can fully adapt to students' natural instincts, mobilize their learning initiative, make use of all kinds of teaching scenarios that are close to real life, and comprehensively train students' English communication skills [26]. VST has effectively promoted the development of spoken English class, with the aid of VST, spoken English class no longer stays at the superficial or lowlevel communication, but deepens into the targeted and effective oral communication and learning $[27,28]$. When designing the virtual scenarios, the designed scenarios mustn't go against the real-life experience of students, but should be in line with the daily routines that are closely related to students [29]. The clear scenario settings and 
definite interpersonal relationships of VST allow students to experience the real relationships in true situations, feel the charm of language in communication, make language learning vivid and interesting, and improve students' spoken English learning efficiency [30].

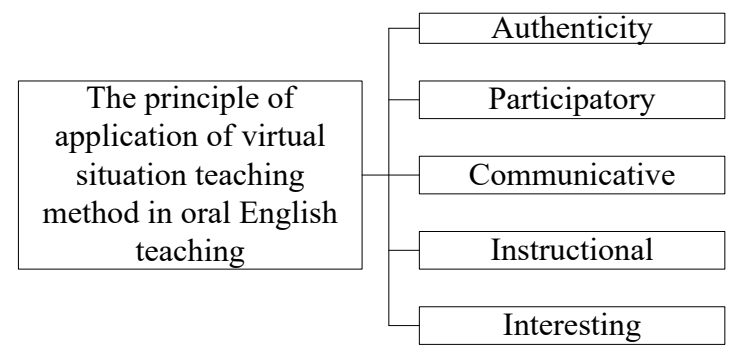

Fig. 1. Principles of applying VST in spoken English teaching

\section{The value of VST in spoken English teaching}

\subsection{The feasibility of VST in spoken English teaching}

With the deepening of international cultural exchange, various cultures of different countries have entered our lives, providing a variety of materials and resources for the creation of virtual scenarios, so the content of the learning materials of spoken English has become wider and freer. The current English materials are generally beautifully illustrated, and accompanied by various medias such as maps, CDs, cards, and color plates, etc., which could create a more realistic language environment for students, and provide massive materials and resources for the input and output of oral English; such excellent textbooks could inspire students' thirst for knowledge and desire for transforming language knowledge into actual communication ability, thereby achieving good teaching effect.

With the application of various technologies in education and the development of teaching environment, current hardware facilities have been gradually improved, which has provided a solid guarantee for teachers to use these facilities to create intuitive and diverse teaching scenarios. Figure 2 shows the classification of language context. The language context can be divided into linguistic context and nonlinguistic context. Situational context belongs to the category of non-linguistic context, it determines the field, tone, and mode of discourse. The situational context makes the classroom forms be more flexible and diverse, and the teaching atmosphere would be more relaxed and energetic. 


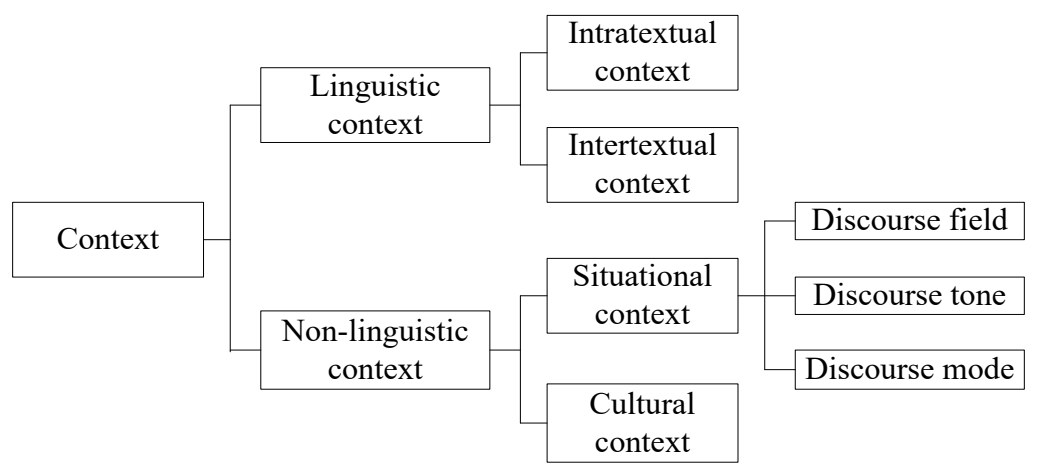

Fig. 2. Classification of language context

\subsection{Strategies for applying VST in spoken English teaching}

Figure 3 lists several proposed strategies for applying VST in the teaching of spoken English. First, the VST should be carried out step by step heuristically and abductively, and the teachers should consider the content and links to be set in the virtual scenarios. Second, the VST should be student-centered, and all virtual scenarios should be set with students' learning requirements as the primary concern. Third, the virtual scenarios should be diversified and realistic, a major advantage of VST is that students can exercise their oral English in the created virtual scenarios, so teachers need to design various scenarios so that students could have real life experience. Fourth, the virtual scenarios should be created based on actual life situations; the goal of learning spoken English is to train students' ability to speak English and use the language to communicate with other in the future, therefore, the teaching activities designed by the teachers should be close to real life so that students could have real feelings, not just practice sentence patterns. Fifth, when students encounter unfamiliar topics, they would feel confused, and the setting of virtual scenarios could greatly alleviate their strange and nervous feelings. Sixth, the virtual scenarios created for VST should combine audios, images, and videos to display the scenarios more vividly, during course teaching, teachers can use these multi-media scenarios and make the class more diversified and efficient, and students would be more interest in the diversified teaching scenarios. 


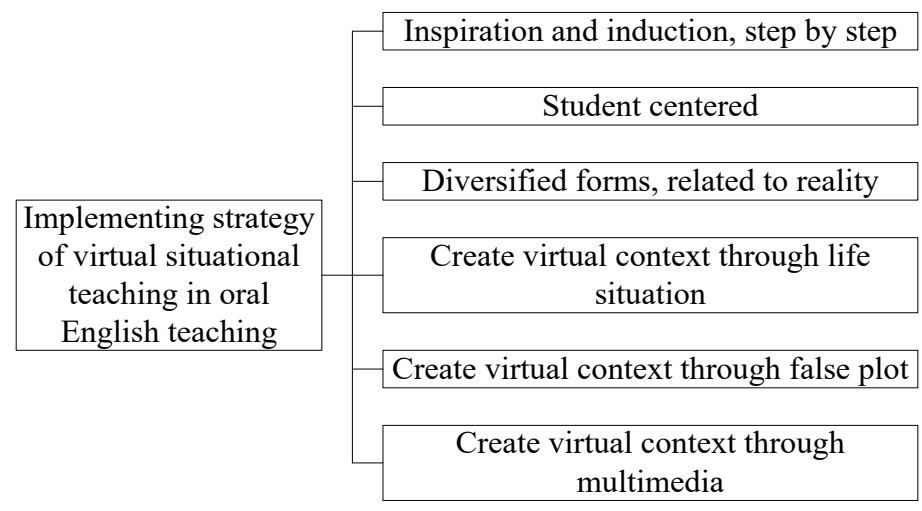

Fig. 3. Strategies for applying VST in spoken English teaching

\section{Status quo of the application of VST in spoken English teaching}

\subsection{Survey results}

To figure out the effect of VST in spoken English teaching, this study chose four schools including one elementary school, two middle schools and one high school in Zhejiang province China to conduct a questionnaire survey. Table 1 shows the statistics of the survey results and the number of issued, returned, and valid questionnaires. Figure 4 shows the statistics of teachers' understanding of VST, it can be seen from the figure that about $70 \%$ of the teachers have an understanding or have a good understanding of the VST, only less than $2 \%$ of the teachers do not have an understanding of VST. Figure 5 shows teachers' attitudes toward VST, it can be seen from the figure that about $95 \%$ of the teachers hold a positive attitude towards VST, and nearly $70 \%$ of them think VST is necessary. Figure 6 shows the statistics of the frequency of teachers applying the VST, in the four surveyed schools, $24.39 \%$ of the teachers apply VST in every class, $52.85 \%$ of them often apply VST, and only $3.25 \%$ of them have never applied VST. Figure 7 shows the difficulties in applying VST. Among these difficulties, the biggest one is the uneven level of student abilities, and the polarization phenomenon is serious; followed by the heavy burden on teachers, and the examination pressure on students; moreover, there're also other difficulties such as the limitation of the quality and professional ability of teachers, and the too much teaching content and too tight teaching time schedule. Figure 8 shows the factors considered by teachers when applying VST. As can be seen in the figure, the proportions of these factors are relatively balanced, and the factors include language ability, time, context, interest and authenticity, and knowledge level. 
Table 1. Statistics of survey results

\begin{tabular}{|c|l|c|c|c|c|}
\hline \multicolumn{2}{|c|}{ Respondents } & Questionnaire & Returned questionnaire & Valid questionnaire & Effective rate \\
\hline \multirow{2}{*}{ School 11 } & Teacher & 18 & 18 & 18 & $100 \%$ \\
\cline { 2 - 6 } & Student & 210 & 207 & 199 & $94.76 \%$ \\
\hline \multirow{2}{*}{ School 1 } & Teacher & 23 & 23 & 22 & $95.65 \%$ \\
\cline { 2 - 6 } & Student & 335 & 331 & 330 & $98.51 \%$ \\
\hline \multirow{2}{*}{ School 1 } & Teacher & 11 & 11 & 11 & $100 \%$ \\
\cline { 2 - 6 } & Student & 196 & 195 & 195 & $99.49 \%$ \\
\hline \multirow{2}{*}{ School 1 } & Teacher & 29 & 29 & 29 & $100 \%$ \\
\cline { 2 - 6 } & Student & 366 & 366 & 364 & $99.45 \%$ \\
\hline
\end{tabular}

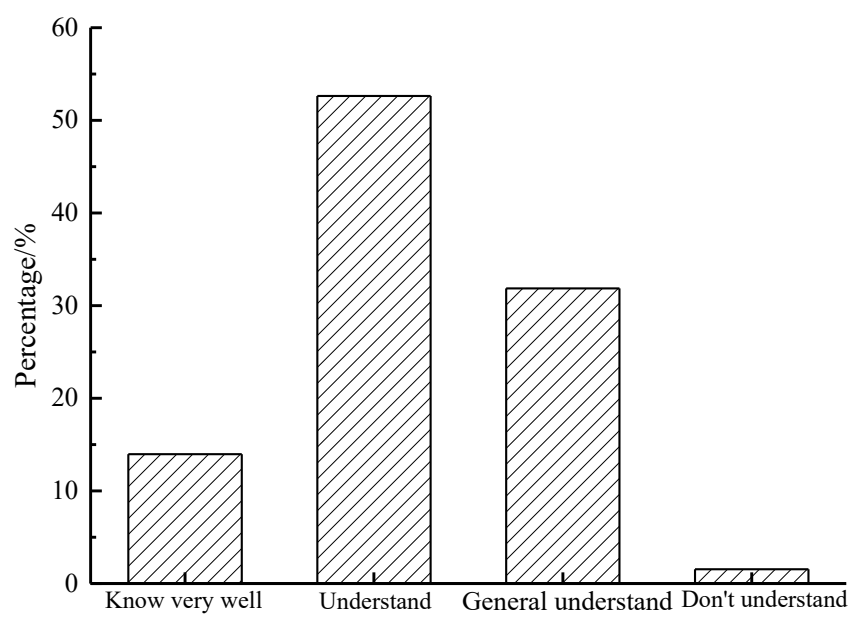

Fig. 4. Statistics of teachers' understanding of VST

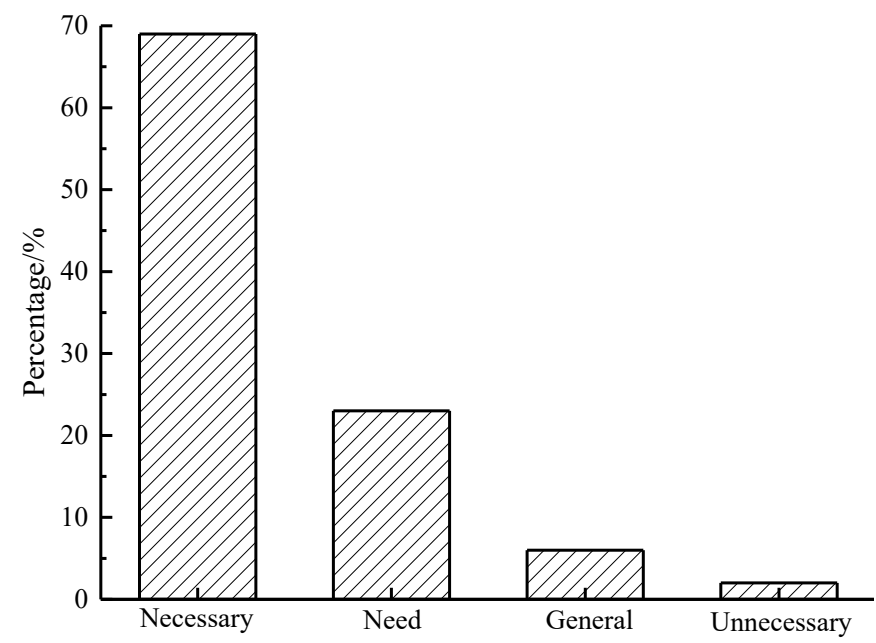

Fig. 5. Teachers' attitudes toward VST 


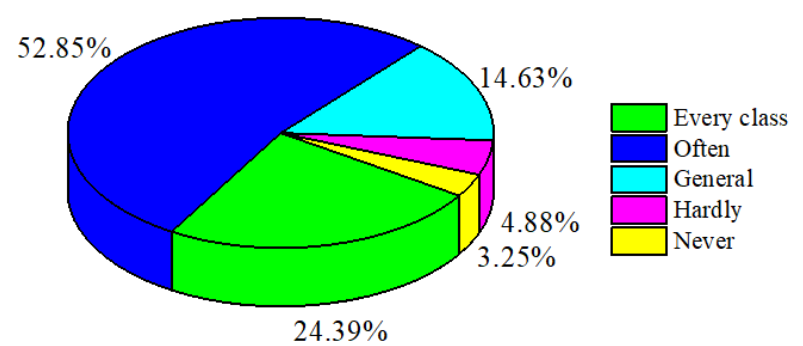

Fig. 6. Frequency of teachers applying VST

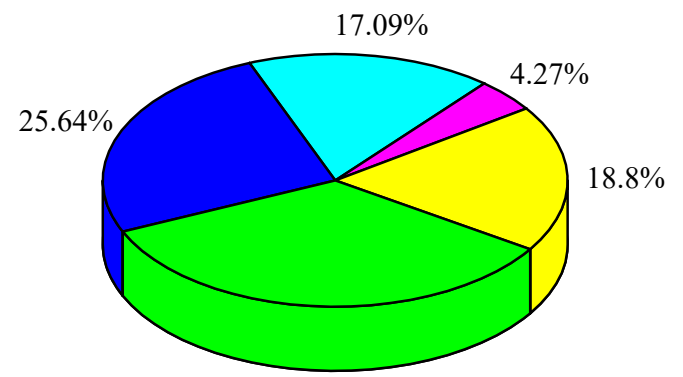

$34.19 \%$

Students' ability level is uneven and polarization is serious Heavy burden on teachers

Examination pressure

The limitation of teachers' quality and professional ability

There are many teaching contents and tight schedule

Fig. 7. Difficulties in applying VST

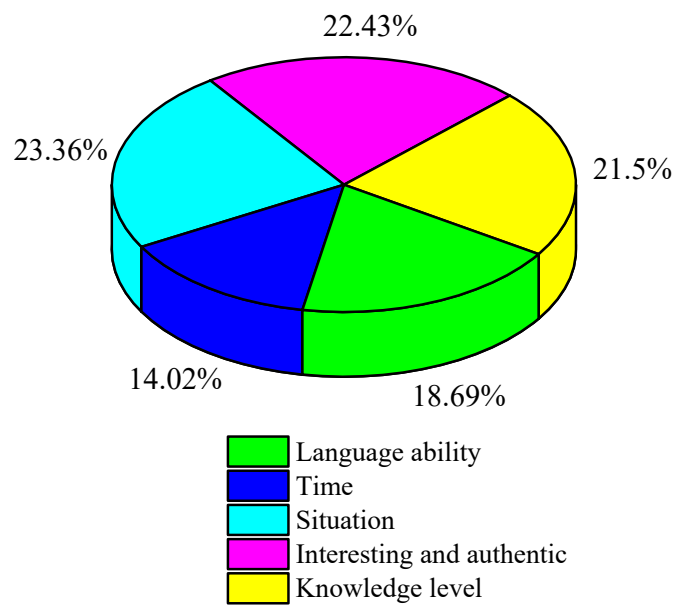

Fig. 8. Factors considered by teachers when applying VST 
Figure 9 is the statistics of students' evaluations on VST. Enhancing language expression ability scored the highest, followed by increasing learning interest, mastering more knowledge, improving learning efficiency, and strengthening oral expression skills. Figure 10 shows the statistics of the means for teachers to apply VST. Using multi-media to create virtual scenarios occupied the largest proportion; followed by using hand gestures, facial expressions, and limb movements to create virtual scenarios; more than $50 \%$ of the teachers often or sometimes use physical objects, pictures, games, and performances to create virtual scenarios. Figure 11 shows the statistics of students' favorite VST methods, the survey results reveal that, the VST methods preferred by students include: playing games using English, performing dialogues with classmates, playing roles in the textbooks, reciting texts, self-introduction using English, talking with teachers, imitating template texts for expression, and free speech using English, etc.

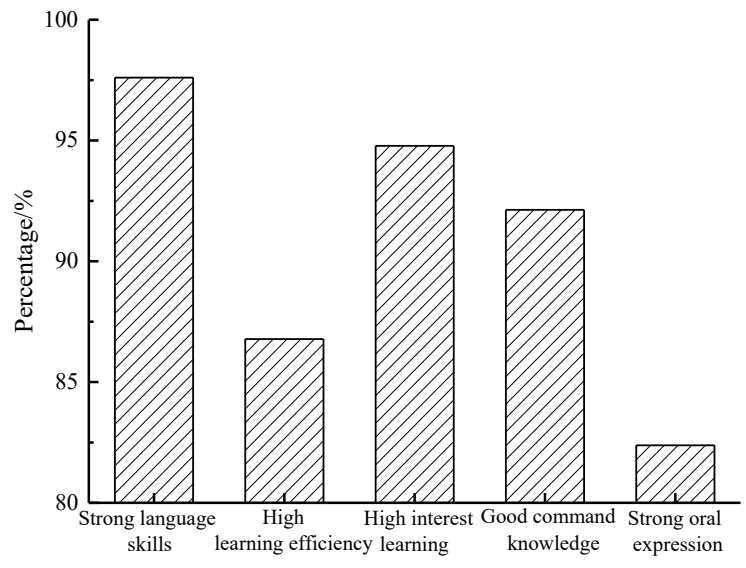

Fig. 9. Statistics of students' evaluations on VST

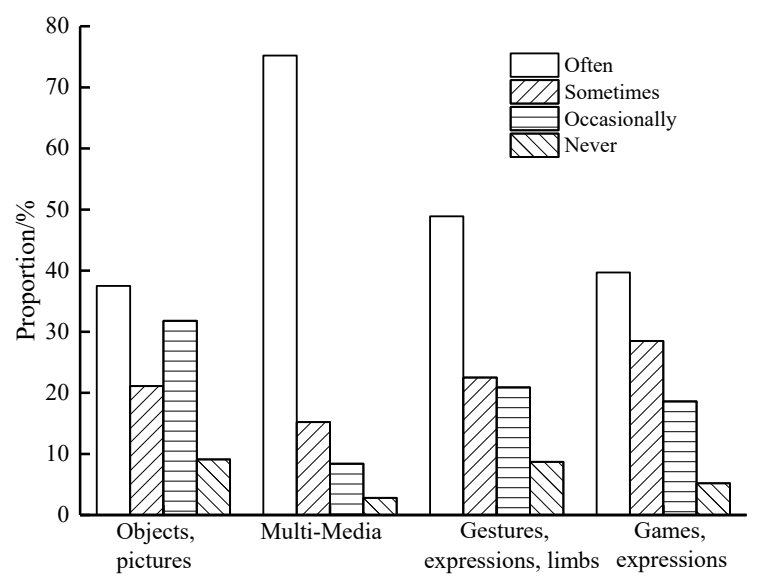

Fig. 10.Statistics of the means for teachers to apply VST 


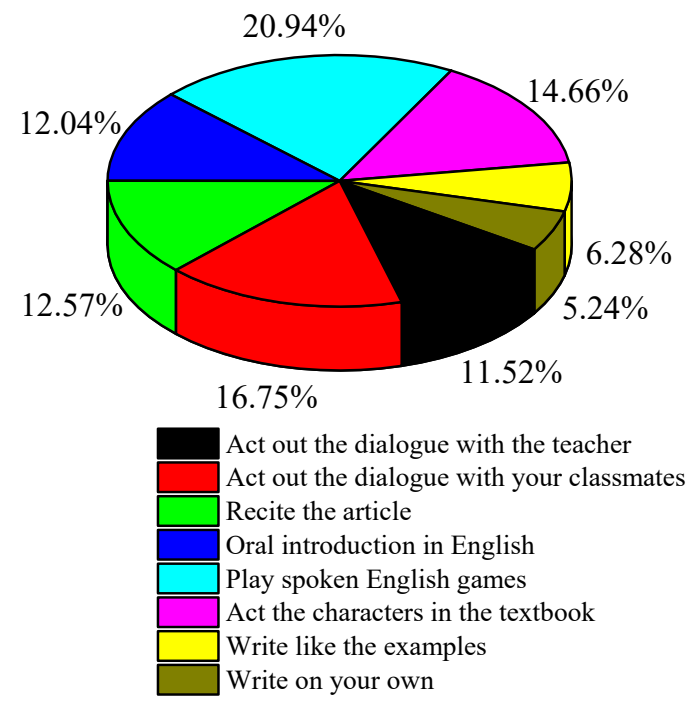

Fig. 11.Statistics of students' favorite VST methods

\subsection{Problems in the application of VST in spoken English teaching}

The lecturing-type English teaching is the main link in traditional English teaching; however, the teaching of spoken English must take students as the subjects of oral expression. In reality, students are of different ability levels, and a same teaching content is not suitable for all students, which has resulted in that students' evaluations on the lecturing content of teachers are quite different. Figure 12 shows the statistics of students' opinions on whether the learning resources could satisfy their spoken English learning requirements, according to the survey results, most students think that the learning resources can occasionally meet their requirements for spoken English learning, and only about $20 \%$ of the students think and the existing learning resources can meet their requirements for spoken English learning.

Figures 13 lists the problems in the application of VST in spoken English teaching. First, the understanding of the connotation of VST is not thorough enough, which causes various scenarios to pile and overlap; second, the course resources haven't been fully developed, and the design of scenarios is not innovative; third, the design method of the virtual scenarios is not as varied, and the designed scenarios are rigid and not real. The main reasons for these problems include that, teachers have a poor awareness of VST; the created scenarios do not match students' cognition level and experience; and the teachers could not effectively organize the activities of VST. 


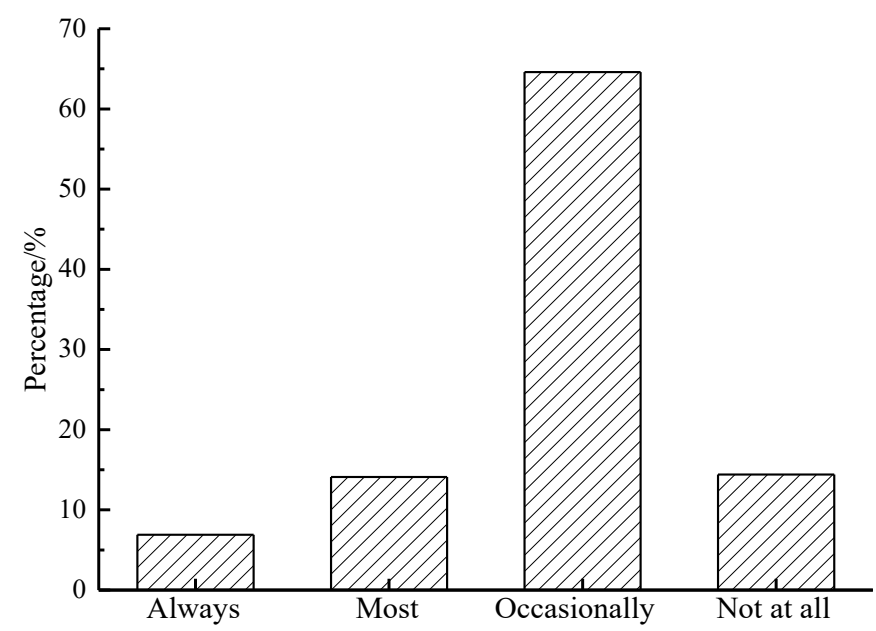

Fig. 12.Statistics of students' opinions on whether the learning resources could satisfy their spoken English learning requirements

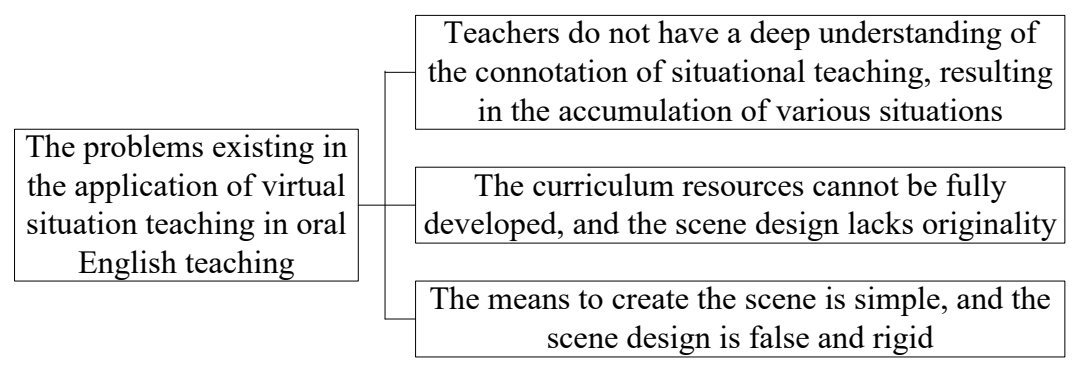

Fig. 13.Problems in the application of VST in spoken English teaching

\subsection{Strategies to improve the effect of spoken English teaching}

There are two parties in the design of VST: teachers and students, so the strategies to improve the effect of spoken English teaching should be given from the perspectives of the two parties. Figure 14 lists the proposed strategies to improve the effect of spoken English teaching. In terms of teachers, the VST should take the teaching goals of spoken English course as the starting point; teachers of spoken English should have solid oral English-speaking skills and teaching ability; they should adapt to the development trend of the era of convergence media, know the development direction of new teaching methods in a timely manner, and learn to integrate the convergence media, the modern information technology, and the teaching of spoken English. In terms of students, they should have good basic English knowledge to lay a foundation for the learning of spoken English; they should form a correct learning motivation, actually, the learning motivation of students changes with the learning activities when they participating in oral English exercises in the class, and students with a positive attitude towards oral English learning could achieve great improvements in their spo- 
ken English exam scores. Moreover, students should actively get familiar with all kinds of spoken English learning strategies, try new things, and accept novel spoken English learning methods.

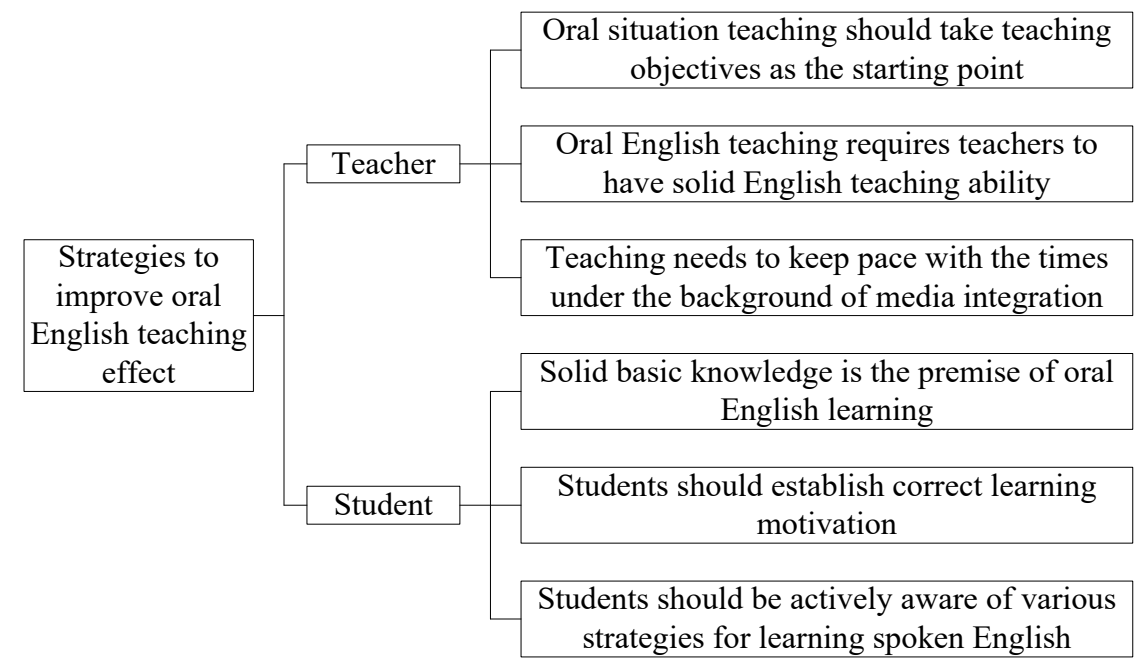

Fig. 14.Strategies to improve the effect of spoken English teaching

\section{Conclusions}

Based on VST, this paper figured out the status quo of spoken English teaching in Chinese schools, and explored the application effect of VST in spoken English teaching. The specific conclusions are as follows:

1. A major advantage of VST is that students can exercise their oral English in the created virtual scenarios, so teachers need to design various scenarios so that students could have real life experience.

2. About $95 \%$ of the teachers hold a positive attitude towards VST, and nearly $70 \%$ of them think VST is necessary. $24.39 \%$ of the teachers apply VST in every class, and $52.85 \%$ of them often apply VST.

3. Applying VST in spoken English teaching could enhance the language expression ability of students, and students' favorite VST method is playing games in English.

\section{References}

[1] Alyssa, K., Kang, O. (2018). Effect of classroom assessment stakes on English language learners' oral performance. TESOL Journal, 10(2): e00392. https://doi.org/10.1002/tesj.392

[2] Wang, Y.J., Zhao, P. (2020). A Probe into Spoken English Recognition in English Education Based on Computer-Aided Comprehensive Analysis, International Journal of Emerging Technologies in Learning, 15(3), 223-233. https://doi.org/10.3991/ijet.v15i03.12937 
Paper-Application of Virtual Scenario Teaching in Spoken English Teaching

[3] Zhang, M. (2020). Virtual Situated Learning of Spoken English Based on Computer Simulation Technology, International Journal of Emerging Technologies in Learning, 15(4), 206-217. https://doi.org/10.3991/ijet.v15i04.12939

[4] Li, X.W. (2018). Integrated teaching model for undergraduate English majors' English public speaking course in China. Creative Education, 9(3): 469-478. https://doi.org/10.423 $\underline{6 / \text { ce. } 2018.93033}$

[5] Huang, W., Li, N., Qiu, Z.J., Jiang, N., Wu, B., Liu, B. (2020). An automatic recognition method for students' classroom behaviors based on image processing. Traitement du Signal, 37(3), 503-509. https://doi.org/10.18280/ts.370318

[6] Guo, Q. (2020). Detection of head raising rate of students in classroom based on head posture recognition. Traitement du Signal, 37(5), 823-830. https://doi.org/10.18280 ts. 370515

[7] Martínez, R.S., Harris, B., McClain, M.B. (2014). Practices that promote English reading for English learners (ELs). Journal of Educational and Psychological Consultation, 24(2): 128-148. https://doi.org/10.1080/10474412.2014.903192

[8] Ahmadian, M.J. (2012). The effects of guided careful online planning on complexity, accuracy and fluency in intermediate EFL learners' oral production: The case of English articles. Language Teaching Research, 16(1): 129-149. https://doi.org/10.1177\%2F13 $\underline{62168811425433}$

[9] Li, M., Li, Y., Guo, H. (2020). Research and application of situated teaching design for NC machining course based on virtual simulation technology. Computer Applications in Engineering Education, 28(3): 658-674. https://doi.org/10.1002/cae.22234

[10] Xiao, X., Liu, X., Xiao, Z. (2021). Construction and application of computer virtual simulation teaching platform for medical testing. Journal of Physics: Conference Series, 1915: 042074. https://doi.org/10.1088/1742-6596/1915/4/042074

[11] Li, X., Xie, Y. (2021). Application of virtual reality technology in oral English teaching for college English majors. Journal of Physics: Conference Series, 1820(1): 012148. https://doi.org/10.1088/1742-6596/1820/1/012148

[12] Li, X., Xie, Y., Liu, T. (2020). Research on oral English teaching system based on VR in the background of ai. Journal of Physics: Conference Series, 1550(2): 022031. https://doi. org/10.1088/1742-6596/1550/2/022031

[13] Yang, Y., Xiao, L. (2019). The construction of college oral English teaching model based on multimodal perspective. Creative Education, 10(2): 423-428. https://doi.org/10.4236 /ce.2019.102030

[14] Li, X. (2021). Research on the establishment of oral Japanese teaching system with Japanese language sense as the main content based on computer software. Journal of Physics Conference Series, 1744(4): 042049. https://doi.org/10.1088/1742-6596/1744/ $4 / 042049$

[15] Tao, Y. (2021). Reflection on teaching research of English applied linguistics based on big data. Journal of Physics Conference Series, 1852(3): 032045. https://doi.org/10.1088/1742$\underline{6596 / 1852 / 3 / 032045}$

[16] Yuan, X. (2021). Design of college English teaching information platform based on artificial intelligence technology. Journal of Physics Conference Series, 1852(2): 022031. https://doi.org/10.1088/1742-6596/1852/2/022031

[17] Wang, X. (2020). Research on the application of computer technology in college English translation teaching. Journal of Physics Conference Series, 1648(3): 032100. https://doi. org/10.1088/1742-6596/1648/3/032100 
[18] Liu, Y., Liu, M. (2019). Research on College English Teaching under the Background of Artificial Intelligence. In Journal of Physics: Conference Series, 1345(4): 042064. https://doi.org/10.1088/1742-6596/1345/4/042064

[19] Chen, Z., Goh, C. (2014). Teacher knowledge about oral English instruction and teacher profiles: an EFL perspective. Teacher Development, 18(1): 81-99. https://doi.org/10.1080 113664530.2013 .854270

[20] Li, G. (2020). The training skills of college students' oral English based on the computeraided language learning environment. Journal of Physics: Conference Series, 1578(1): 012040. https://doi.org/10.1088/1742-6596/1578/1/012040

[21] Nguyen, H.T., Warren, W., Fehring, H. (2014). Factors Affecting English language teaching and learning in higher education. English Language Teaching, 7(8): 94-105. https://doi.org/10.5539/elt.v7n8p94

[22] Lewis, M. (2011). Primary English teaching: an introduction to language, literacy and learning. Language \& Education, 25(6): 564-566. https://doi.org/10.1111/j.1741-4369. 2012.00659.x

[23] Noor, N.B.M., Muniandy, M.K., Shanmugam, S.K.K., Mathai, E.J. (2010). Upper primary teachers' perceptions of PSLE English oral assessment. English Language Teaching, 3(4): 142-151. https://doi.org/10.5539/elt.v3n4p142

[24] Ho, P.V.P. (2014). The effects of communicative grammar teaching on students' achievement of grammatical knowledge and oral production. English Language Teaching, 7(6): 74-86. https://doi.org/10.5539/elt.v7n6p74

[25] Alali, F.A., Schmitt, N. (2012). Teaching formulaic sequences: the same as or different from teaching single words. Tesol Journal, 3(2): 153-180. https://doi.org/10.1002/tesj.13

[26] Ren, X. (2021). The practice and thinking of computer virtual reality technology in the teaching mode of physical education in colleges and universities. Journal of Physics Conference Series, 1744(4): 042020. https://doi.org/10.1088/1742-6596/1744/4/042020

[27] Ketelhut, D.J., Nelson, B., Schifter, C., Kim, Y. (2013). Improving science assessments by situating them in a virtual environment. Education Sciences, 3(2), 172-192. https://doi. org/10.3390/educsci3020172

[28] Darius, P.L., Portier, K.M., Schrevens, E. (2007). Virtual experiments and their use in teaching experimental design. International Statistical Review, 75(3): 281-294. https://doi.org/10.1111/j.1751-5823.2007.00028.x

[29] Greenfader, C.M., Brouillette, L., Farkas, G. (2015). Effect of a performing arts program on the oral language skills of young English learners. Reading Research Quarterly, 50(2): 185-203. https://doi.org/10.1002/rrq.90

[30] Delaney, T. (2012). Quality and quantity of oral participation and English proficiency gains. Language Teaching Research, 16(4): 467-482. https://doi.org/10.1177/13621688 $\underline{12455586}$

\section{$7 \quad$ Authors}

Mengqing Han graduated from North China University of Science and Technology with a master's degree in English interpretation in 2015. She is now working at Shijiazhuang University of Applied Technology. The main research direction is English teaching, English translation, English literature and intercultural communication (email: han9876789@126.com).

Shanshan Niu graduated from North China University of Science and Technology with a master's degree in English translation in 2015. She is now working at Huaxin 
Paper-Application of Virtual Scenario Teaching in Spoken English Teaching

College of Hebei GEO University. The main research direction is English teaching, intercultural communication, comparison of Chinese and Western cultures, knighthood in Medieval Western Europe.

Article submitted 2021-07-01. Resubmitted 2021-07-29. Final acceptance 2021-07-29. Final version published as submitted by the authors. 